\title{
A computationally efficient cohesive zone model for fatigue
}

DOI:

10.1111/ffe.12927

\section{Document Version}

Accepted author manuscript

Link to publication record in Manchester Research Explorer

\section{Citation for published version (APA):}

Salih, S., Davey, K., \& Zou, Z. (2018). A computationally efficient cohesive zone model for fatigue. Fatigue \& Fracture of Engineering Materials and Structures , 42(2), 518-532. https://doi.org/10.1111/ffe.12927

\section{Published in:}

Fatigue \& Fracture of Engineering Materials and Structures

\section{Citing this paper}

Please note that where the full-text provided on Manchester Research Explorer is the Author Accepted Manuscript or Proof version this may differ from the final Published version. If citing, it is advised that you check and use the publisher's definitive version.

\section{General rights}

Copyright and moral rights for the publications made accessible in the Research Explorer are retained by the authors and/or other copyright owners and it is a condition of accessing publications that users recognise and abide by the legal requirements associated with these rights.

\section{Takedown policy}

If you believe that this document breaches copyright please refer to the University of Manchester's Takedown Procedures [http://man.ac.uk/04Y6Bo] or contact uml.scholarlycommunications@manchester.ac.uk providing relevant details, so we can investigate your claim.

\section{OPEN ACCESS}




\title{
A computationally efficient cohesive zone model for fatigue
}

\author{
S. Salih", K. Davey, Z. Zou \\ School of Mechanical, Aerospace and Civil Engineering, The University of Manchester.
}

\begin{abstract}
A cohesive zone model has been developed for the simulation of both high and low cycle fatigue-crack growth. The developed model provides an alternative approach that reflects the computational efficiency of the well-established envelop-load-damage model yet can deliver the accuracy of the equally well-established loading-unloading hysteresis damage model.

A feature included in the new cohesive zone model is a damage mechanism that accumulates as a result of cyclic plastic separation and material deterioration to capture a finite fatigue life. The accumulation of damage is reflected in the loading-unloading hysteresis curve but additionally the model incorporates a fast-track feature. This is achieved by "freezing in" a particular damage state for one loading cycle over a predefined number of cycles.
\end{abstract}

The new model is used to simulate mode I fatigue crack growth in austenitic stainless steel 304 at significant reduction in the computational cost.

Keywords: Fatigue crack growth modelling, cohesive model, UMAT subroutine

\footnotetext{
* sarmed.salih@manchester.ac.uk (S. Salih)

keith.davey@manchester.ac.uk (K. Davey)

zhenmin.zou@manceshter.ac.uk (Z.Zou)
}

\section{NOMENCLATURE}

$\begin{array}{ll}a^{\mathrm{cz}} & \text { Cohesive zone length } \\ D^{\mathrm{c}} & \text { Cyclic damage } \\ D^{\mathrm{s}} & \text { Static damage } \\ E & \text { Elastic modulus } \\ K^{\mathrm{coh}} & \text { Cohesive stiffness } \\ G^{\mathrm{c}} & \text { Total dissipated energy per unit area }\end{array}$




$\begin{array}{ll}G^{\mathrm{p}} & \text { Dissipated plastic energy in the cohesive zone per unit area } \\ N & \text { Number of cycles } \\ N^{\mathrm{f}} & \text { Number of cycles to fail the cohesive element } \\ \Delta N & \text { Number of cycles in the load envelope } \\ N^{\mathrm{u}} & \text { Number of required damage updates } \\ \Gamma^{\mathrm{o}} & \text { Critical cohesive energy } \\ \delta^{\mathrm{c}} & \text { Critical separation } \\ \delta_{1} & \text { Shape parameter for the linear and trapezoidal model respectively } \\ \delta_{2} & \text { Second shape parameter of the trapezoidal model } \\ \delta^{\mathrm{p}} & \text { Plastic separation } \\ \delta^{\text {cyc }} & \text { Cyclic displacement } \\ \delta^{\text {cyc }} & \text { Maximum displacement reached at the loading cycle } \\ \delta & \text { Separation in the CE } \\ \delta^{\mathrm{max}} & \text { The separation at the onset of unloading } \\ \sigma^{\mathrm{c}} & \text { Critical cohesive stress } \\ \sigma & \text { Cohesive stress } \\ \sigma^{\mathrm{Y}} & \text { Yield stress } \\ \sigma^{\text {max }} & \text { The stress at the onset of unloading } \\ \vartheta & \text { Poisson's ratio }\end{array}$

Abbreviation

$\mathrm{CZ}$

Cohesive zone

$\mathrm{CE}$

Cohesive element

CZM

Cohesive zone model

LEFM Linear elastic fracture mechanics

TCZM Trapezoidal Cohesive zone model

TSL Traction separation law

\section{INTRODUCTION}

Engineering structures such as bridges, power plants, airplanes, trains, cars and others have played an important role in human life since the beginning of the industrial revolution. However, these structures can suffer from mechanical failures caused by crack propagation leading potentially to catastrophic events, loss of human life and significant financial cost. 
Fatigue phenomena have been the subject of research for more than 150 years. However, complete solutions for this issue have not yet been discovered ${ }^{1}$. Great effort has been made to understand and evaluate the crack growth behaviour under cyclic loading. However, fatigue remains an area of active research with the development of new materials and physical models. All current models used in the description of fatigue behaviour suffer from limitations and none are able to capture the extensive experimental evidence available in the literature.

It is apparent from the academic literature that the cohesive zone model (CZM) is presently considered to be an attractive approach when combined with the finite element method to simulate fracture and fatigue problems. Nevertheless, an optimum CZM able to simulate any form of crack growth problem remains elusive. It is well appreciated in the literature that cyclic loading makes any crack propagation problem more complex, involving an unloading part of the loading cycle along with a process that is history dependent. The vast majority of crack propagation studies presented in the literature involving a CZM are limited to monotonic crack growth prediction. Therefore, in order to use the CZM for fatigue crack growh simulation an irreversible and history-dependent cohesive law is required. Any such law must be able to account for and accommodate the damage accumulation associated with cyclic loading ${ }^{2}$. This can in principle be achieved by identifying additional criteria for the development of internal variables in any CZM thus providing history dependence. In the literature, there are two available models for identifying this cyclic history dependence, i.e. the envelope-load damage model and the loading-unloading hysteresis damage model.

The maximum load of the loading cycle is the focus of the envelope-load damage model rather than a description of the complete cyclic loading behaviour. All variants founded on this particular approach formulate a damage rate. Although the damage rate for convenience is written here in the form of a derivative it should be well appreciated that the damage rate is not in fact a derivative as is a path-dependent quantity and as such is not a function. The damage is assumed composed of a quasi-static damage and a cyclic damage, which are considered to be additive to provide the total damage

The damage accumulated specific number of cycles the integration of the damage rate over the interval form is defined via the integration of damage rate. Thus, after a damage is determined from the current damage plus and explicitly takes the 
The integral in Eq.(1), is typically approximated using 2-point Newton-Cotes quadrature; for example in references ${ }^{3,4}$ the approximation takes the form

or alternatively with a 1-point Newton-Cotes quadrature as in references ${ }^{5-10}$, which takes the form

A source of error in Eq. (3), is the loss of the quasi-static damage rate, which cannot be estimated by means of the 1-point Newton-Cotes quadrature as explained in reference ${ }^{11}$. Different formulations for the cyclic damage rate, found in the literature, are reviewed in reference ${ }^{11}$. A fatigue CZM that can be applied for high cycle fatigue analysis of mode I, mode II and mixed mode can be found in references ${ }^{3,4,12-14}$. A particular concern with the damage rate equations adopted in these models is the number of material parameters involved; each requiring experimentation for their determination and for each loading mode. To reduce the cost required for calibrating parameters, the damage evolution can be linked to a Paris-like model as in references ${ }^{5-10}$. Linking damage evolution to a Paris-law means no additional parameters require calibration other than the standard Paris-law parameter. Unfortunately, with this approach, predictive accuracy is affected since growth is confined by the particular growth law assumed to apply. Accuracy is also influenced by the integration scheme employed to integrate the damage rate equation. An additional contributory factor can be the absence of the component describing the quasi-static damage rate. Damage evolution can be directly related to the cohesive zone length (or at least to the fatigue part of the cohesive zone length). In references 5-10 for instance, the cohesive zone length is evaluated using

or a modified version of this equation, where is the cohesive zone length (the length of the process zone ahead of the crack tip where active cohesive elements are present); is the critical energy release rate, is Young's modulus of the bulk material in the direction 
perpendicular to the crack plane and is the cohesive strength. The link to cohesive zone length in this way is essentially non-physical and consequentially cannot be measured or quantified experimentally.

Unlike the envelope-load approach, the entire loading-unloading cycle is considered and represented in loading-unloading hysteresis damage models. This permits the modelling of advanced behaviour at the cohesive interface and surroundings taking into consideration such things as friction and plasticity ${ }^{11}$. Loading-unloading hysteresis models are based on the reduction of the interfacial stiffness captured by a cyclic damage variable that evolves or an internal variable that grows; a review of CZMs for fatigue can be found in references ${ }^{15-18}$. The first successful attempt to use a CZM for the simulation of fatigue crack growth is presented in reference ${ }^{19}$, which introduces a cyclic damage variable , whose purpose is to quantify the amount of dissipated energy in the fracture process divided by the critical fracture energy. Variable interfacial stiffness models soon followed this work (see references ${ }^{20,21}$ for example), where traction rate is assumed to be a function of incremental stiffnesses and according to the relationship,

where and are loading and unloading stiffness, respectively and is the rate of change of separation.

A particular deficiency with these models is that crack defects are assumed to grow no matter how small they might be, which can be unrealistic behaviour. To correct for this, introduced in reference ${ }^{22}$ are two additional parameters and , which represent the endurance limit and the accumulated cohesive length, respectively. If the component of stress normal to the crack at the element ahead of the crack tip is less than the endurance limit, then the model presents an infinite life (no crack will propagate). Although this model contains the basic features necessary for describing fatigue crack growth, like all previous models, it remains phenomenological requiring validation with experimental results to check accuracy and to standardize the cohesive zone parameters. Other studies ${ }^{18,23-25}$ have considered similar approaches. Although, the loading-unloading hysteresis damage model replicates to an extent, fatigue behaviour over each and every time increment, it is rather costly in terms of 
computational time and from a practical viewpoint it is unfeasible for high-cycle fatigue simulation, where analysis can typically involve extremely large numbers of loading cycles.

To overcome the cost associated with hysteresis damage models, de-Andrés ${ }^{19}$ introduced an extrapolation scheme to estimate the damage state after a specific number of cycles by a twoterm Taylor expansion of the form

The rate of change of per cycle at , required for the extrapolation is computed by a detailed step-by-step computation of a few loading cycles. A limitation of this method is the assumption that the damage rate is constant throughout the crack propagation period. In addition, for good accuracy, the cycle increment is constrained by the requirement that the damage increment is relatively small. Similar methods are considered in references ${ }^{26,27}$.

In general, fatigue modelling using the CZM looks very promising but is still in its infancy with no mature CZMs yet available for use in industrial applications ${ }^{11}$. However, in an attempt to advance the approach this paper introduces a loading-unloading hysteresis damage model containing a fast-track feature.

The new CZM is introduced in Section 2 along with the fast-track feature and a mechanism for capturing irreversibility. The implementation of the new CZM model in the commercial software package ABAQUS (via a bespoke UMAT subroutine) is discussed in Section 3. In addition, the analysis model properties (geometry, material properties, and boundary conditions) along with a mesh-sensitivity analysis are considered. Section 4 focuses on the validation of the new model by presenting, discussing and comparing results with experimental fatigue data. Conclusions are presented in Section 5.

\section{COHESIVE ZONE MODEL FOR FATIGUE}

The fracture process can be simplified to the form shown in Fig. 1, where the behaviour of the material element at the crack tip is assumed to follow a predefined traction separation law (TSL). Different forms of TSLs used in the literature include polynomial, exponential, bilinear, and trapezoidal shapes as shown in Fig. 2. A cohesive model is not physical but 
phenomenological and attempts to represent the physics of the fracture process by means of a single separating interface. Therefore, there is no physical evidence for the shape of the function that relates traction to separation. The effect of the traction-separation law shape is discussed in reference ${ }^{28}$, where it is concluded that the shape of the law does not significantly affect the analysis results. However, it is shown in references ${ }^{29-32}$ that the TSL has an effect on fracture behaviour but the significance of this effect depends on geometry and material properties.

For a pre-defined TSL, two of the cohesive parameters

are usually sufficient for simulating the fracture process, where is the energy dissipated in the formation of new surfaces, is the critical cohesive traction and is the critical cohesive separation at which the cohesive element fails. The trapezoidal cohesive zone model (TCZM) on the other hand involves an additional shape parameter ( ), which is required to be specified to simulate the complete fracture process. The addition of this parameter is to account for local plasticity at the crack tip, so avoiding the need for a global elastic-plastic analysis in a situation where only localised plasticity is involved. This feature is advantageous computationally as it permits an elastic-bulk material to be assumed. The area under the traction curve represents the total dissipated energy ( $\quad$ (i.e. the plastic energy dissipated in the local plastic zone and the energy required to form new surface), which is represented mathematically as

which for a trapezoidal cohesive model depicted in Fig. 1 gives

where is the total dissipated energy per unit area, is the local plastic dissipated energy, is the displacement at which the deformation become permanent, and is the displacement at which the element deterioration is assumed to start.

The standard TCZM is represented mathematically as, 
where is the cohesive traction, which represents the cohesive stiffness of an undamaged cohesive element. Similarly is the cohesive stiffness of a damaged cohesive element (which initially equals ) and is defined by

where and are the separation and stress at the onset of unloading; these initially take the values and , respectively to ensure if no damage is present in the cohesive element.

Note that for the standard TCZM at unloading the crack is fully closed and the cohesive traction is returned to zero following the relationship (the model does not account for crack closure). The subsequent reloading follows the same path as illustrated in Fig. 1. As advised by Scheider et al. ${ }^{33}$ the value of should be very small and the value of should be close to . Therefore, in this study these values are set to

The damage process is assumed to be void initiation, growth and coalescence, which is represented by the parameter in the cohesive model. For the TCZM the damage variable can be represented by the relationship

which has the rate form , where is a positive function of the form 
and as above, rate is conveniently represented symbolically here, in the form of a derivative, i.e.

and

If cyclic loading is applied, the standard TCZM will result in an infinite life. Therefore, it is necessary to use an irreversible and history dependent CZM in order to capture finite life. This can be done by identifying a cyclic damage mechanism.

\subsection{Fatigue Cohesive Model}

The damage mechanism used for the new TCZM consists of two parts. First is the cyclic damage , which itself is associated with two distinct effects: (i) an increase in local plastic separation when and; (ii) for a further increase in as consequence of void growth and coalescence. Second is monotonic damage that results from material deterioration not attributed to cyclic loading in the CZM. These two features are shown to be sufficient for the TCZM to capture fatigue crack growth.

A schematic outline of the behaviour of the proposed model is presented in Fig. 3, with traction represented mathematically by

where in this model the critical cohesive stress doubles up as the endurance limit, which is the stress level required for activating the damage accumulation mechanism; loads resulting in stresses below in the cohesive zone will result in an infinite life. The Heaviside function

is defined to zero when is smaller than and one in other cases. Finally, is the damage variable of Eq. (13), The separation has two parts, i.e. 
where is the cyclic displacement as a result of the applied load at any time increment, with plastic separation updated by means of integration of a rate relationship, i.e.

where is the stored plastic separation from the previous loading cycle, and the rate of change in plastic separation (represented here in the form of a derivative for convenience), i.e. the increase in the plastic separation per cycle.

The integral in Eq. (17) can be approximated using the mean value theorem for integration. If is assumed to be defined and smooth on the interval $(\mathrm{N}, \mathrm{N}+1)$, then

where belongs to the interval $[\mathrm{N}, \mathrm{N}+1]$, is an intermediate value of the rate

, which in this work is assumed to be proportional to the maximum separation , reached at the end of a loading cycle. This assumption provides a convenient approximation of the form,

where is a positive dimensionless constant of proportionality and takes a value greater than unity to reflect the fact that only a proportion of contributes to plastic separation..

Note that the origin of Eq. (19) is a rate equation of the form , where $\mathrm{h}$ is a positive function. The exact form the function $\mathrm{h}$ takes is not important here since the approximation adopted in Eq. (19) is sufficient and expedient since is dependent on the loading conditions (to account for the loading history) with any material cyclic damage being readily captured by the material parameter, which can be tuned to accommodate particular material behaviour on comparing analysis results with experimental data. The dimensionless parameter provides an indication of the rate at which plastic separation is taking place in a material and consequently is material dependent. It is however independent of the specimen shape and loading conditions and once determined for a particular material 
can in principle be applied to any loading case. Substitution of Eq. (19) into Eq. (17) yields an extraordinarily simple increment rule for cyclic damage, i.e.

Shown in Fig. 4(a) is the behaviour of the cohesive model under cyclic loading and the accumulated dissipated energy is readily shown to be

represented by the area under the traction-separation curve in Fig. 4.

\subsection{Fast-track feature}

The model described in Section 2.1 can be shown to represent fatigue behaviour, but suffers from a particular limitation. In its present form (similar to the loading-unloading hysteresis damage model) it is practically unfeasible and computationally costly requiring excessively long computational time as a consequence of the large numbers of cycles typically involved in any realistic industrial application. In order to overcome this particular limitation, it is necessary to find an approach that limits the extent of the computational requirements. An observation of the behaviour of the existing model however, is that deviation in the cyclic behaviour tends to evolve extremely slowly. Cyclic damage is considered here to be a combination of cyclic plastic separation and material deterioration and it is the cyclic plastic separation that is observed to suffer low cyclic deviation. This suggests that a reasonable approximation is a linear growth rule for cyclic plastic separation with constant plastic increment over a specific load envelope containing cycles. This simple observation provides the founding idea for the new fast-track procedure.

Consider then the possibility that the rate of change in cyclic plastic separation evaluated in a loading cycle remains constant for a specific load envelope containing number of cycles; the value of should not be set at a value too high to allow damage to be updated to maintain accuracy. The cyclic plastic separation after $(\quad$ is evaluated in the usual way as 


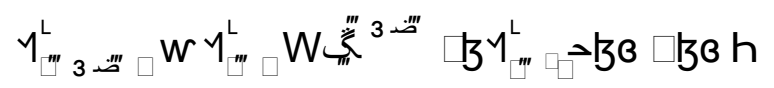

Similar to Eq. (17), the integral in Eq. (22) is approximated using the mean value theorem for integration and on applying the approximation in Eq. (19), the cyclic plastic separation after (в W

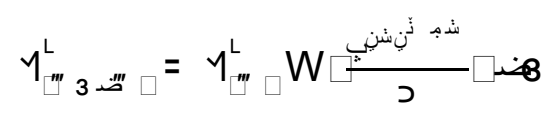

where Eq. (20) is returned on setting $\mathrm{W} \square$

The increment for computational expediency can be any integer value significantly greater than one but accuracy is a limiting consideration. It is important therefore to have some understanding about the effect has on the accuracy of the fast-track procedure. A simple procedure (not connected to fatigue analysis per se) is adopted for the sole purpose to provide a reasonable estimate for the value of cycle. From this cycle, information is recovered at the integration point (IP) at the crack tip, with being set by the relationship,

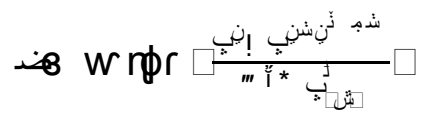

where $\phi r$ is a function that returns the nearest integer to the argument, ${ }^{\circ}{ }^{8}$ is a parameter that represents the number of required updates of the cyclic damage, $Y_{b \square}^{L}$ is the cyclic plastic separation after the first loading cycle, and $\bar{\Upsilon}^{\pi} \pi^{\circ}$ and $\eta^{\pi}$ are the maximum cyclic displacement reached at the loading cycle and the critical cohesive separation, respectively. The numerator $\mathrm{Y}^{\pi} \mathrm{W}^{\pi} \mathrm{U}^{\pi^{\circ}}$ in Eq. (24) is a relatively crude approximation of the cyclic

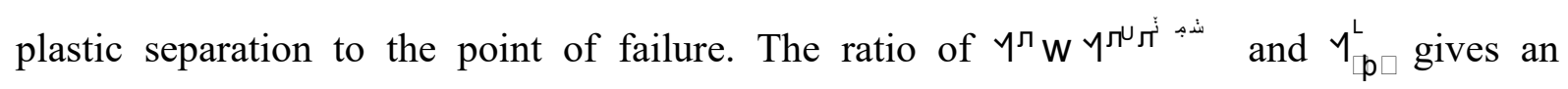
indication of the number of cycles that leads to the failure of the IP at the crack tip. The value

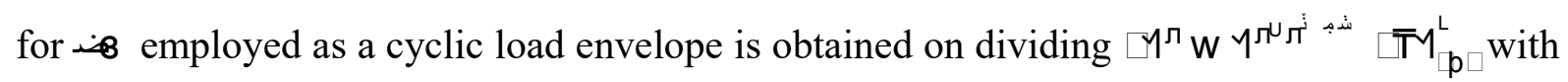
the integer ${ }^{\curlyvee}{ }^{~}$ (representing the number of cyclic updates deemed necessary for accuracy) and returning the nearest integer. The greater the value of ${ }^{\circ}{ }^{b}$ the lower the value of (with $\stackrel{+}{+} \square \square$ but consequently the greater the computational cost.

The predicted value of by Eq. (24) is estimated in a one-cycle analysis and the final value is applied as a fixed input to all the cohesive elements in the fatigue analysis along with $(\mathrm{V} \ddot{\mathrm{W}}$ 
$Y^{\top}+\phi 3 D$ ) for all cohesive elements. The value of (with $\mathrm{o}^{\circ}$ fixed) will automatically be higher if the problem under consideration involves high-cycle fatigue since both the maximum cyclic displacement and the cyclic plastic increment will be smaller. A detailed investigation on the effect of on the simulation results is provided in Section 3.3.

The separation $Y^{\prime} P^{\top}$ and the stress $V^{\prime} P^{\top}$ at the end of the $B$ Cycles are determined with

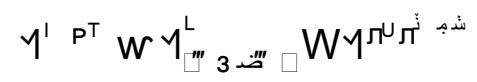

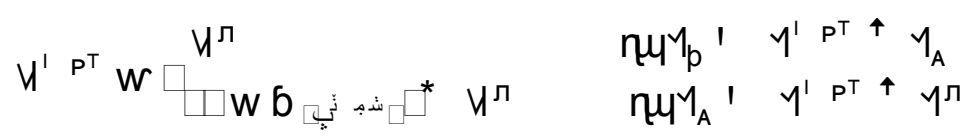

Thus, after $\boldsymbol{B}$ W cycles, Eq. (26) returns the maximum stress, which is equal to the cohesive critical stress if $Y^{\prime} P^{\top}$ (from Eq. (25)) is less than $Y_{A}$. If however, $Y^{\prime} P^{\top}$ is larger than $Y_{A}$, then the maximum stress $U^{\prime} P^{\top}$ is evaluated in a similar fashion to Eq. (15), by using the monotonic damage variable $b$ of Eq. (13), with $Y$ replaced by $Y^{\prime} \mathrm{P}^{\top}$. The evaluated values from Eq. (25) and (26) are provided to the next loading cycle along with the new value of $Y$ at $\mathrm{B} W \dot{B}$, with $Y$ determined using Eq. (16) and applied in Eq. (15).

To keep things reasonably simple is assumed to remain invariant for the total process. To record the exact number of cycles when the cohesive element fails and bearing in mind that at

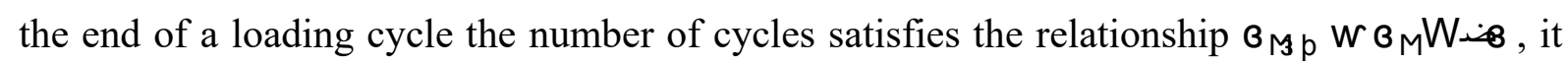
is necessary to compare the value of $Y^{\prime} P^{\top}$ (evaluated by using Eq. (25)) with $Y^{\top}$ and if larger, then the number of cycles at which the element failed satisfies the relationship

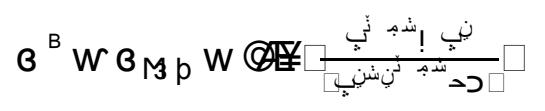

The second term on the right hand side of Eq. (27), represents the unwanted number of cycles that do not contribute to failure. The numerator $Y^{\prime} P^{\top} W^{\top}$ represents the cyclic damage as a

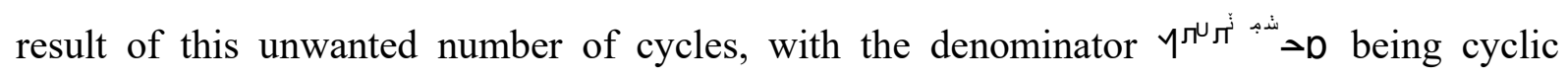

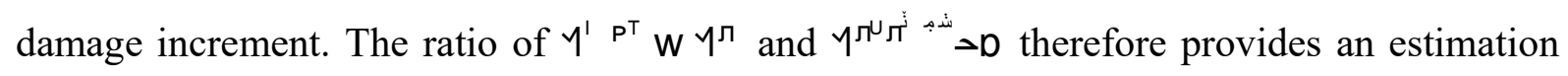
of the overshoot in the prediction of the number of cycles to failure and hence must be removed as shown in Eq. (27). 


\section{IMPLEMENTATION OF THE NEW CZM IN ABAQUS}

The commercial finite element solver ABAQUS is used as a vehicle for the numerical analysis in this study. In ABAQUS, the fracture process using the cohesive model can be identified either by a cohesive surface or by cohesive elements that are situated along the crack path. In this study, cohesive elements are used although existing elements in ABAQUS are somewhat constrained by TSLs that are history independent and not applicable for the simulation of fatigue crack growth. However, the TSL can be defined through their material behaviour and ABAQUS provides a facility to specify new material behaviour (as the new cohesive model introduced in this study) through a user-defined material subroutine.

\subsection{UMAT Implementation and Testing}

To test the UMAT subroutine, a three-element model (two continuum elements and one cohesive element connecting them) is used as shown in Fig. 5. The material properties in the bulk material and the cohesive element are shown in Table 1 . The parameter $C$ is set to have a small value (i.e. 40) to artificially reduce the number of cycles required for failure of the cohesive element. The load is applied as a cyclic displacement with fixed maximum amplitude of $\square \grave{y}^{*} \square \square^{\ominus} \mathrm{m}$ and $\mathrm{R}=0$. The analysis is performed initially on a cycle by cycle basis (i.e. $W \square$ ) and then with the new fast-track technique on setting $\mathbf{W} \square$. The cyclic stress of the new fatigue model (in a cycle by cycle manner first and by using the new technique with $\mathbf{W} \square$ ) are shown with respect to the separation and time in Fig. 4 and Fig. 6, respectively. The graphs shown in Fig. 4 reveal how the model can readily cater for an initially high load resulting in a correspondingly high level of energy dissipation and monotonic damage apparent in the first cycle. This is then followed by cyclic damage at significantly lower levels of dissipation per cycle. Also shown in Fig. 4 is the growth of the plastic separation with the number of cycles until the separation $\mathcal{Y}_{\text {reaches }} \mathcal{Y}_{A}$, at which point the cohesive stiffness decreases with increasing number of cycles because of material deterioration leading to failure of the cohesive element. The required analysis time for a typical element to fail using the cycle-by-cycle model (dashed curve) and the fast-track model (solid curve) is shown in Fig. 6. It reveals that the fast-track procedure provides a reduced number of cycles and hence computational effort, which of the order of $!^{p}$ of that required without its implementation. The figure shows that for an analysis involving 26 
loading cycles the fast-track procedure takes some $140 \mathrm{~s}$ whilst the cycle-by-cycle analysis takes $560 \mathrm{~s}$.

\subsection{Analysis Model: Geometry and Boundary Conditions}

The finite element model depicted in Fig. 7 conforms to the shape of the specimens used in the fatigue experimental trials. The numerical model consists of 23618 plane-stress elements of which 22988 (type CPS4), 390 (type CPS3), and 240 cohesive elements (type COH2D4) 34 . The material properties for the bulk material element and the cohesive element are found in Table 2. The initial values of the cohesive parameters were set as follows: $\eta^{\pi}$ equals the crack tip opening displacement (CTOD) as measured experimentally in a CT specimen and equals $0.000168 \mathrm{~m}$; the value of the critical cohesive stress was set to equal the material yield stress and its value is $340 \mathrm{MPa}$.

The new fatigue algorithm is initiated with a cycle-by-cycle analysis with these initial values for a few hundred cycles to determine the correct value of the parameter $C$, which is obtained by means of curve fitting analysis results and contrasting with experimentally obtained fatigue data. The final value of $C$ is subsequently used in a one-cycle analysis to obtain an optimum value of , which is chosen to provide good accuracy for a substantially reduced computational effort. In the present model the selected value of is applied over the full fatigue analysis; the parameter set in Table 2 was found to give the best fit.

The boundary conditions applied to the analysis model are shown in Fig. 7. Loading is in the form of a uniform cyclic displacement in the y-direction applied at the top surface and fixed in all directions at the bottom surface. The load is applied in twenty steps: first a ramp load that increases from zero to $\square \grave{y} \square^{*} \square \square{ }^{{ }^{8}} \mathrm{~m}$ followed by nineteen steps with sinusoidal load at

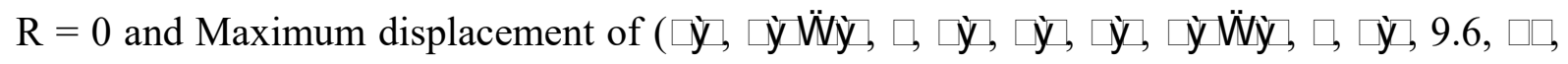
$\square \check{y} \mathbf{W} \square \grave{y}, \square \grave{y}, \square \square, \square \check{y}, \square \square \grave{y})^{*} \square !^{\circledR} \mathrm{m}$, respectively as shown in Fig. 8. The number of cycles in each step is $6400,3200,2400,1600,1600,1600,1600,1600,1600,800,800,800$, $800,800,800,800,800,800$, (the last step is run until failure), respectively. The number of cycles at each step is set to ensure that the loading conditions match to those of the fatigue experiment. 


\subsection{Fast-track effect on accuracy of the result}

The effect of the updates-parameter ${ }^{\gamma}$ found in Eq. (24) (and consequently 8 ) on the damage variable and the dissipated energy as tested on the three-element model is shown in Table 3, Figures 9 and 10 and its effect on the crack growth on full model is shown in Figures 11 and 12. In general, a decrease in the value of $\mathrm{o}^{\succ}$ (increasing the value of $\mathrm{B}$ ) gives rise to a predicted slower crack growth. From Table 3, the error in the estimated number of cycles at failure and the value of the damage variable $b$ is found to be dependent on the value of $\sigma^{8}$,

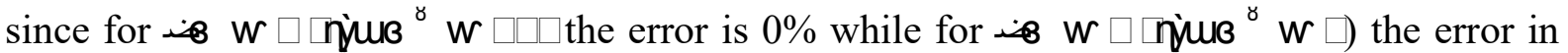
the predicted result is $4 \%$. The error in the simulation results becomes significant when ${ }^{\circ}{ }^{8}$ is set to a small value, for example the error in the case when $\mathbf{W} \square \square$ inuy ${ }^{\circ}{ }^{\circ} \mathrm{W} \square$ ) is $24 \%$. The results indicate the expected behaviour that the greater the value of ${ }^{\gamma}{ }^{\gamma}$ is (and hence lower value of ) the reduction in observable differences is. From Table 3, Figs. 9 and 10 it is observable that there is little dependence of the results on the value of in the virtualplastic region (i.e. when $Y^{\prime} P^{\top} \uparrow Y_{A}$ ). However, differences become more noticeable in the region of material deterioration (i.e. $Y^{\prime} P^{\top}, Y_{A}$ ). However, revealed in Fig. 10 is that acceptable results are achievable if is such that the damage is updated reasonably regularly (i.e. $\mathrm{o}^{\curlyvee}$ is not too low). From the results shown in Figs. 11 and 12, it can be concluded that any value higher than 6 for the updates-parameter ${ }^{\circ}$ provides satisfactory results with a significant reduction in computational cost. It is clear from Fig. 11, that the predicted results are reasonably close to each other for values of ${ }^{\circ}{ }^{\gamma}$ set to $(56,28,14,7)$, which correspond to $=\square=\square \square \mathbb{W} \square \square \mathbb{W} \square \square \mathbb{W} \square \square \square$, respectively. Differences are more noticeable however for values of $\mathrm{o}^{\gamma}$ lower than 6 , where $\mathrm{s}^{\gamma} \mathrm{W} \square$ corresponds to $=2000$ and $\mathrm{B}^{\gamma} \mathrm{W} \square$ corresponding to $=5600$, as shown in Fig. 12. In this study, a value of $\mathrm{B}^{\gamma} \mathrm{W} \square$ corresponding to $=\square \square \square$, was found to be sufficient for good accuracy and a significant reduction in numerical analysis time. The analysis of the problem under consideration took just few hours on a PC platform with $\mathrm{o}^{\mathrm{\gamma}} \mathrm{W} \square \mathrm{W} \square \square[$ The ratio of cpu time with the fast-track procedure over the CPU-time with the cycle by cycle analysis is of the order of 1 ! $p$. 


\subsection{Mesh Sensitivity Analysis}

Converged results have been confirmed by running a mesh sensitivity analysis. Increasing the overall number of bulk-material elements or the cohesive zone elements has been found to have little impact on the results presented. However, it might well be anticipated that the number of elements in the cohesive zone will be critical to a good outcome. The length of the cohesive zone represents the distance between the actual crack tip and the analytical crack tip. This zone includes the active cohesive elements and it directly linked to the crack-tip plastic zone, so its length can be estimated through a similar formulation to the plastic zone estimated by von Mises yield criterion as

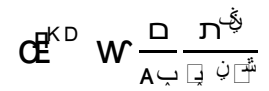

For the problem under consideration the length of the cohesive zone is $8.4 \mathrm{~mm}$, whereas the length of the ligament is $20 \mathrm{~mm}$. It is possible to deduce from the plots shown in Fig. 13 that the number of cohesive elements in the cohesive zone, only has a minor influence on the crack growth and fatigue life. However, if the focus is to accurately represent the stress field at the crack tip, a higher number of elements is required (see Fig. 14). In this work, 101 cohesive elements in the cohesive zone are employed to ensure that numerical errors are insignificant.

\section{RESULTS AND DISCUSSION}

To overcome the inherent limitations of the loading-unloading hysteresis damage model, a new cohesive zone model with fast track facility has been introduced. This model is founded on the basis of loading-unloading hysteresis but with the facility to "freeze in" damage for a loading cycle over a predefined number of cycles. The damage is updated in the next loading cycle to comply with the conditions at the new state at $\mathrm{B}$ W cycles. The approach has been proven to be efficient in terms of time and computational cost reduction. Analyses that can require months or possibly years to be solved (depending of the computational platform) using a cycle by cycle approach can be resolved in just a few hours or few days to a good accuracy. Shown in Fig. 15 is experimental and predicted crack length versus the number of cycles; Although the crack growth curve predicted with the new approach (with shows a delay in crack initiation and a temporary crack arrest at the early stages of crack 
growth, the overall predicted crack propagation is in good agreement with the experimental data. The deviant behaviour at crack initiation is as a consequence of the time required to fully develop a stable cohesive zone as shown in Fig. 15. The cohesive model in this sense differentiates between a virgin crack and a crack developed through fatigue.

One advantage of the new model over the previous models proposed in the literature ${ }^{19,26,27,35}$, is its simplicity. The model does not require the establishment of a relationship that links the damage to the number of cycles as in previous work. The damage in this case is calculated for one cycle and applied over cycles and then updated automatically for the next loading cycle. Another advantage of the model is that is automatically set according to the problem (low cycle fatigue or high cycle fatigue) and incorporates a technique to evaluate the accurate number of cycles at failure rather than simply assuming it is a multiple of .

\section{CONCLUSIONS AND FUTURE WORKS}

- A new trapezoidal cohesive zone model for fatigue that can be applied for high and low cycle fatigue simulations has been introduced.

- Decreasing the value of $\mathrm{B}^{\curlyvee}$ is observed to lower crack growth. If however, $\mathrm{o}^{ð}$ is set so that the damage variable is sufficiently updated (after 800 cycles proved sufficient in the tests), then the results can be expected to be in good agreement with the experimental data with significant reduction in computational costs.

- The new CZM model has been shown to provide acceptable results with a significant reduction in the cost in terms of the computational time of the order of $b$.

- It is observed that the model tends to overestimate the crack length at crack initiation for crack lengths less than $1.2 \mathrm{~mm}$ but subsequently the predicted crack length is in line with experimental data.

- Additional experimental testing is needed to provide additional evidence on the uniqueness of the dimensionless material parameter $\mathrm{C}$.

- The new procedure has only been tested under mode I loading conditions but good outcomes are anticipated for mixed-mode analysis. 


\section{ACKNOWLEDGEMENTS}

The authors would like to acknowledge the Higher Committee for Education Development in Iraq and the College of Engineering at Babylon University for providing support for Sarmed Salih to facilitate his doctoral research at the University of Manchester.

\section{REFERENCE}

1. Farahmand B. Virtual Testing and Predictive Modeling. Springer Science+Business Media; 2009. http://link.springer.com/content/pdf/10.1007/978-0-387-95924-5.pdf. Accessed March 3, 2014.

2. Li H, Yuan H. Cohesive zone modelling of low cycle fatigue cracks in cracked and notched specimens. Fatigue Fract Eng Mater Struct. 2013;36:1246-1257. doi:10.1111/ffe.12061.

3. Robinson P, Galvanetto U, Tumino D, Bellucci G, Violeau D. Numerical simulation of fatigue-driven delamination using interface elements. Int J Numer Methods Eng. 2005;63(13):1824-1848. doi:10.1002/nme.1338.

4. Tumino D, Cappello F. Simulation of Fatigue Delamination Growth in Composites with Different Mode Mixtures. J Compos Mater. 2007;41(20):2415-2441. doi:10.1177/0021998307075439.

5. Turon A, Costa J, Camanho P, Mayugo J. Simulation of delamination propagation in composites under high-cycle fatigue by means of cohesive zone models. NASA Tech Rep. $2006 . \quad$ http://www.iccmcentral.org/Proceedings/ICCM16proceedings/contents/pdf/WedG/WeGA1-03spturona225067p.pdf.

6. Turon A, Costa J, Camanho PP, Dávila CG. Simulation of delamination in composites under high-cycle fatigue. Compos Part A Appl Sci Manuf. 2007;38(11):2270-2282. doi:10.1016/j.compositesa.2006.11.009.

7. Pirondi A, Moroni F. A Progressive Damage Model for the Prediction of Fatigue Crack Growth in Bonded Joints. $J$ Adhes. 2010;86(5-6):501-521. doi:10.1080/00218464.2010.484305. 
8. Harper PW, Hallett SR. A fatigue degradation law for cohesive interface elements Development and application to composite materials. Int J Fatigue. 2010;32(11):17741787. doi:10.1016/j.ijfatigue.2010.04.006.

9. Pirondi A, Moroni F. Simulation of Mixed-Mode I/II Fatigue Crack Propagation in Adhesive Joints with a Modified Cohesive Zone Model. J Adhes Sci Technol. 2011;25(18):2483-2499. doi:10.1163/016942411X580180.

10. Bak BLV, Turon A, Lindgaard E, Lund E. A Benchmark Study of Simulation Methods for High-Cycle Fatigue-Driven Delamination Based on Cohesive Zone Models. Compos Struct. 2016. doi:10.1016/j.compstruct.2016.11.081.

11. Bak BL V., Sarrado C, Turon A, Costa J. Delamination Under Fatigue Loads in Composite Laminates: A Review on the Observed Phenomenology and Computational Methods. Appl Mech Rev. 2014;66(6). doi:10.1115/1.4027647.

12. de Moura MFSF, Gonçalves JPM. Cohesive zone model for high-cycle fatigue of adhesively bonded joints under mode I loading. Int J Solids Struct. 2014;51(5):11231131. doi:10.1016/j.ijsolstr.2013.12.009.

13. De Moura MFSF, Gonçalves JPM. Development of a cohesive zone model for fatigue/fracture characterization of composite bonded joints under mode II loading. Int J Adhes Adhes. 2014;54:224-230. doi:10.1016/j.ijadhadh.2014.07.002.

14. de Moura MFSF, Gonçalves JPM. Cohesive zone model for high-cycle fatigue of adhesively bonded joints under mode I loading. Int J Solids Struct. 2014;51(5):11231131. doi:10.1016/j.ijsolstr.2013.12.009.

15. Liu J, Li J, Wu B. The Cohesive Zone Model for Fatigue Crack Growth. Adv inMechanical Eng. 2013.

16. Kuna $\mathrm{M}$, Roth S. General remarks on cyclic cohesive zone models. Int J Fract. 2016;(196):147-167. doi:10.1007/s10704-015-0053-y.

17. Zan DQ, Sun Q, Pan HL, Chen JJ, Wang ZD. Application of the cohesive zone model for analysing the edge crack propagation of steel sheet in the cold rolling process. Fatigue Fract Eng Mater Struct. 2017;40(6):869-881. doi:10.1111/ffe.12548.

18. Khoramishad H, Crocombe AD, Katnam KB, Ashcroft IA. Predicting fatigue damage 
in adhesively bonded joints using a cohesive zone model. Int $J$ Fatigue. 2010;32(7):1146-1158. doi:10.1016/j.ijfatigue.2009.12.013.

19. De-Andrés A, Pérez J, Ortiz M. Elastoplastic finite element analysis of threedimensional fatigue crack growth in aluminum shafts subjected to axial loading. Int $J$ Solids

Struct. 1999;36(15):2231-2258. http://www.sciencedirect.com/science/article/pii/S0020768398000596. Accessed April 8, 2014.

20. Nguyen O, Repetto E. A cohesive model of fatigue crack growth. Int J Fract. 2001;110:351-369. http://link.springer.com/article/10.1023/A:1010839522926. Accessed March 21, 2014.

21. Yang B, Mall S, Ravi-Chandar K. A cohesive zone model for fatigue crack growth in quasibrittle materials. Int $J$ Solids Struct. 2001;38(22-23):3927-3944. doi:10.1016/S0020-7683(00)00253-5.

22. Roe KL, Siegmund T. An irreversible cohesive zone model for interface fatigue crack growth simulation. Eng Fract Mech. 2003;70(2):209-232. doi:10.1016/S00137944(02)00034-6.

23. Beaurepaire P, Schuëller GI. Modeling of the variability of fatigue crack growth using cohesive zone elements. Eng Fract Mech. 2011;78(12):2399-2413. doi:10.1016/j.engfracmech.2011.05.011.

24. Ural A, Krishnan VR, Papoulia KD. A cohesive zone model for fatigue crack growth allowing for crack retardation. Int J Solids Struct. 2009;46(11-12):2453-2462. doi:10.1016/j.ijsolstr.2009.01.031.

25. Khoramishad H, Crocombe a. D, Katnam KB, Ashcroft I a. Fatigue damage modelling of adhesively bonded joints under variable amplitude loading using a cohesive zone model. Eng Fract Mech. 2011;78(18):3212-3225. doi:10.1016/j.engfracmech.2011.09.008.

26. Towashiraporn P, Subbarayan G, Desai CS. A hybrid model for computationally efficient fatigue fracture simulations at microelectronic assembly interfaces. Int $J$ Solids Struct. 2005;42(15):4468-4483. doi:10.1016/j.ijsolstr.2004.12.012.

27. Koutsourelakis PS, Kuntiyawichai K, Schuëller GI. Effect of material uncertainties on 
fatigue life calculations of aircraft fuselages: A cohesive element model. Eng Fract Mech. 2006;73(9):1202-1219. doi:10.1016/j.engfracmech.2006.01.003.

28. Tvergaard V, Hutchinson JW. The relation between crack growth resistance and fracture process parameters in elastic-plastic solids. $J$ Mech Phys Solids. 1992;40(6):1377-1397. doi:10.1016/0022-5096(92)90020-3.

29. Falk ML, Needleman A, Rice JR. A critical evaluation of cohesive zone model of dynamic fracture. In: Proceedings of the 5th, Journal de Physique IV, Proceedings 11(Pr.5). ; 2001:43-50. http://arxiv.org/abs/cond-mat/0106304.

30. Zhang X, Mai Y-W, Jeffrey RG. A cohesive plastic and damage zone model for dynamic crack growth in rate-dependent materials. Int $J$ Solids Struct. 2003;40(21):5819-5837. doi:10.1016/S0020-7683(03)00370-6.

31. Alfano G, Barros S De, Champaney L, Valoroso N. Comparison Between Two Cohesive-Zone Models for the Analysis of Interface Debonding. Eur Congr Comput Methods Appl Sci Eng. 2004:1-18. http://imechanica.org/files/Alfano-BarrosChampaney-Valoroso-ECCM04.pdf.

32. Salih S, Davey K, Zou Z. Rate-dependent elastic and elasto-plastic cohesive zone models for dynamic crack propagation. Int J Solids Struct. 2016;90:95-115. doi:10.1016/j.ijsolstr.2016.04.002.

33. Scheider I, Schödel M, Brocks W, Schönfeld W. Crack propagation analyses with CTOA and cohesive model: Comparison and experimental validation. Eng Fract Mech. 2006;73(2):252-263. doi:10.1016/j.engfracmech.2005.04.005.

34. ABAQUS. ABAQUS 6.13 User Guide. USA: Dassault Systèmes Simulia Corp; 2013. http://129.97.46.200:2080/v6.13/.

35. Bak BL V, Lindgaard E, Lund E, Turon A. Performance of cohesive zone models for fatigue driven delaminations. In: 11th World Congress on Computational Mechanics. ; 2014:1-2.

36. Schwalbe K, Scheider I, Cornec A. Guidelines for Applying Cohesive Models to the Damage Behaviour of Engineering Materials and Structures. Berlin, Heidelberg: Springer Berlin Heidelberg; 2013. doi:10.1007/978-3-642-29494-5. 


\section{FIGURES}

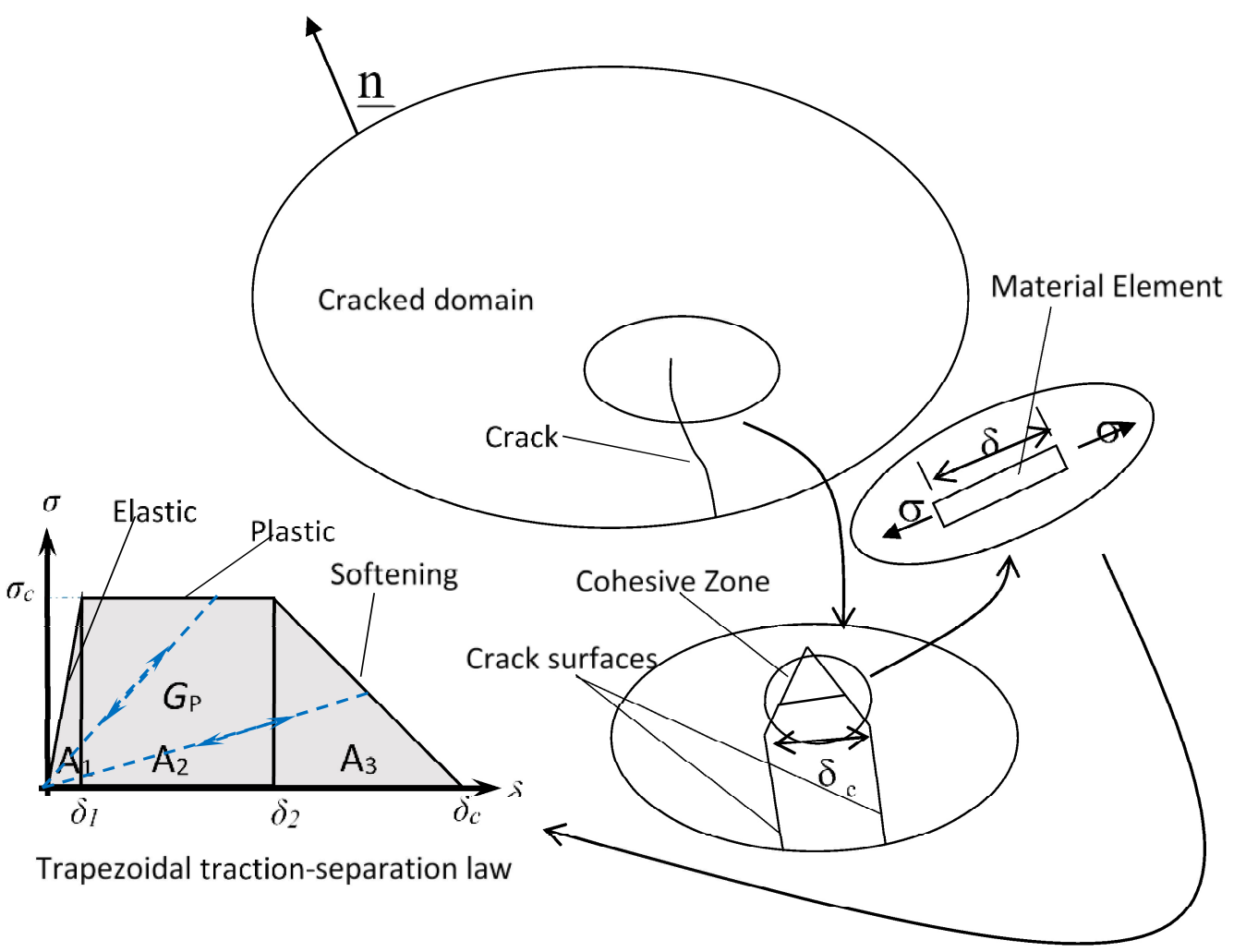

Figure 1. Mode I Cohesive-Zone model ${ }^{32}$.

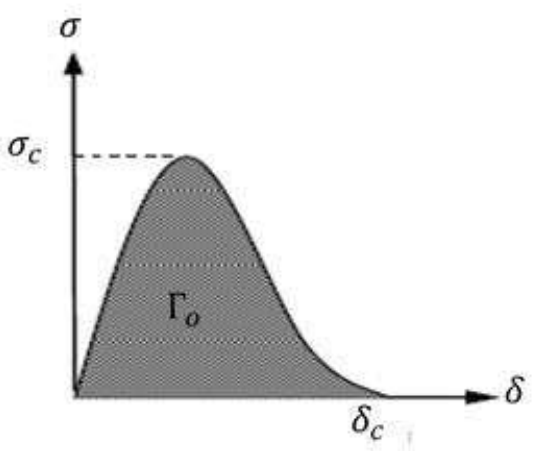

(a) Polynomial

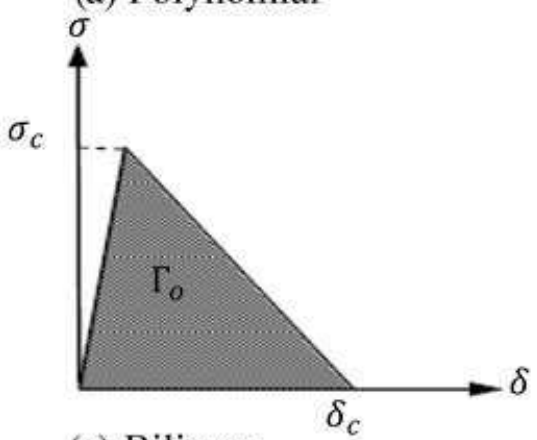

(c) Bilinear

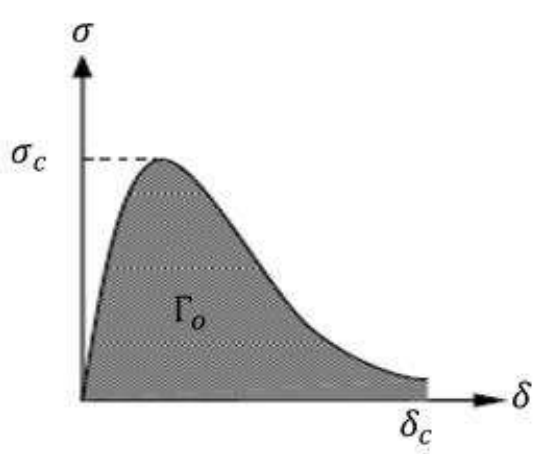

(b) Exponential

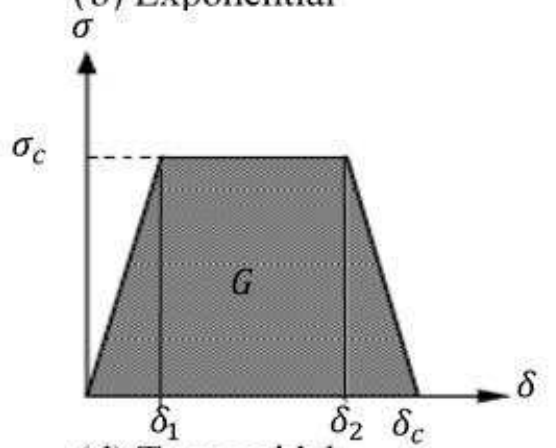

(d) Trapezoidal

Figure 2 The widely used traction separation laws: a) Polynomial,

b) Exponential, c) Bilinear, d) Trapezoidal ${ }^{36}$. 


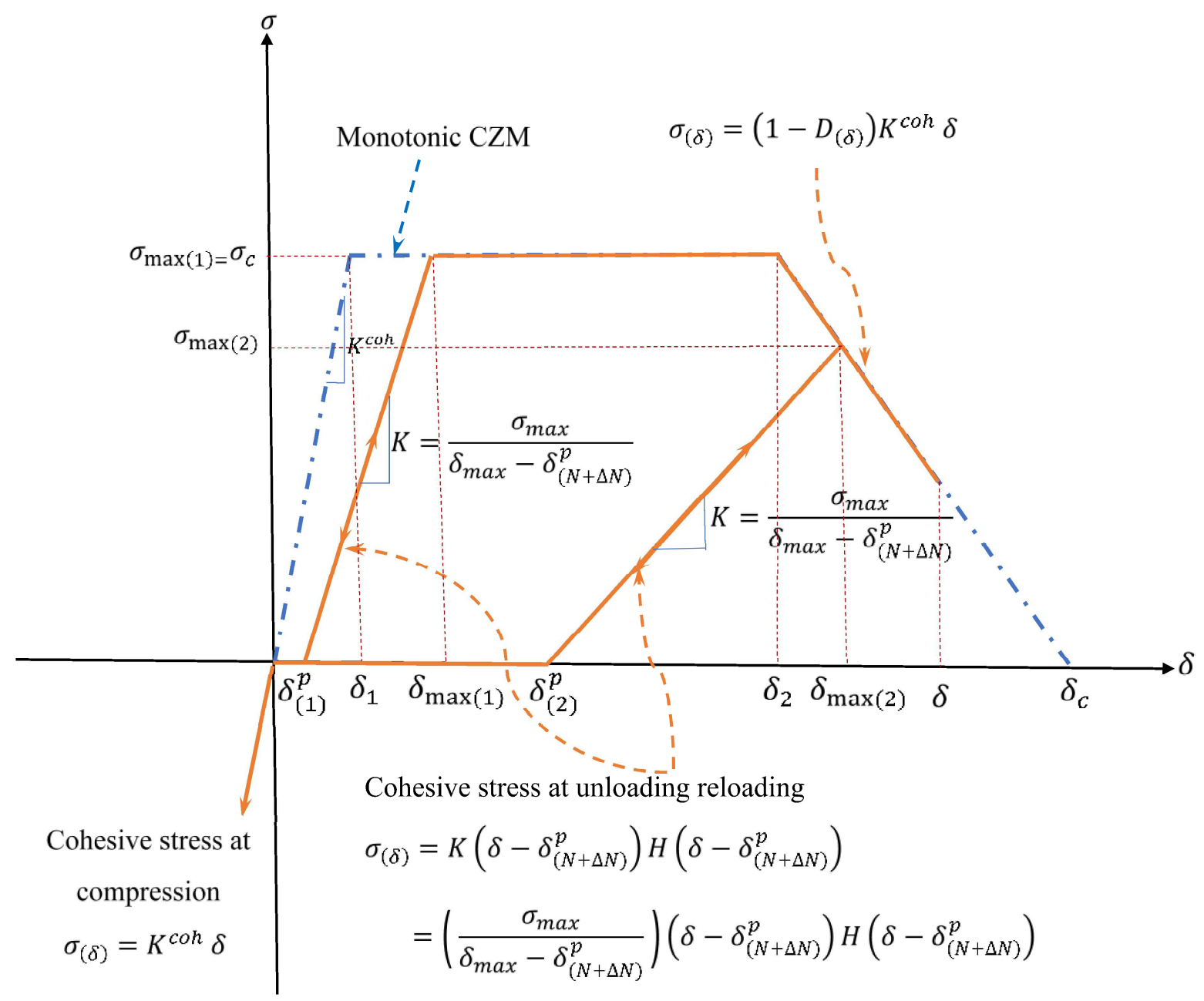

Figure 3. New loading-unloading hysteresis model. 


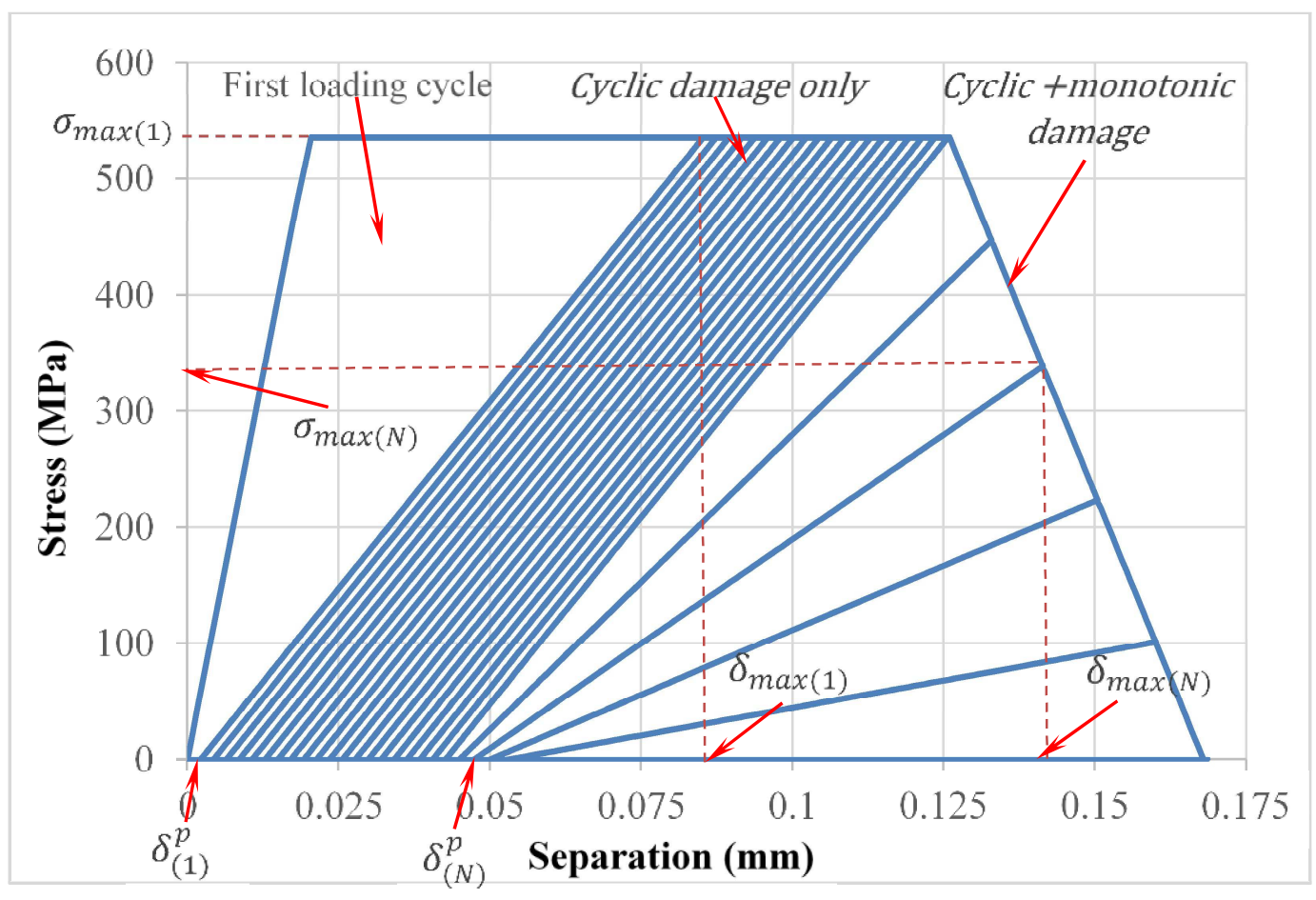

(a) Cycle by cycle

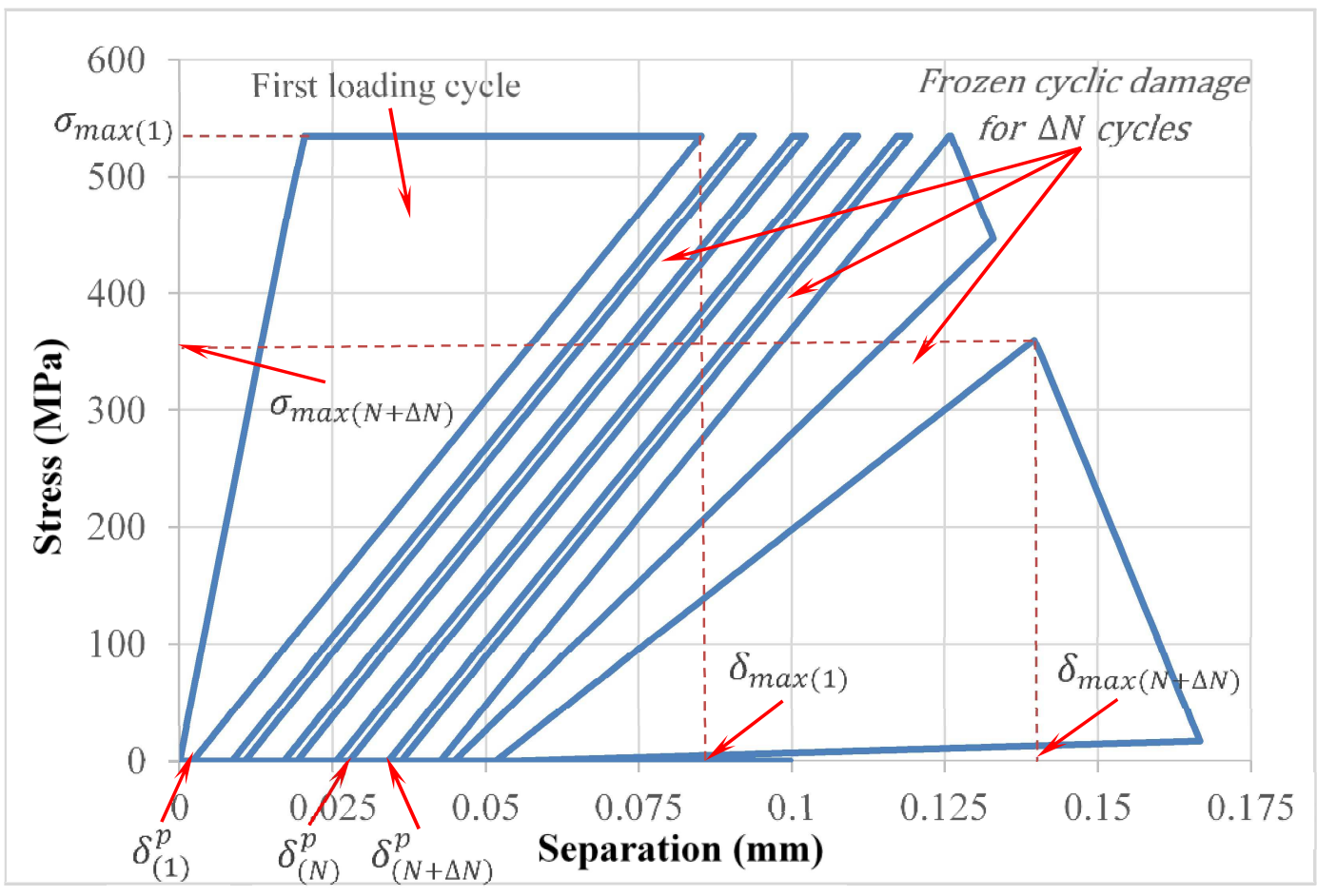

(b) Fast-track procedure with $\Delta N=4$

Figure 4. Cyclic stress-separation curves. 


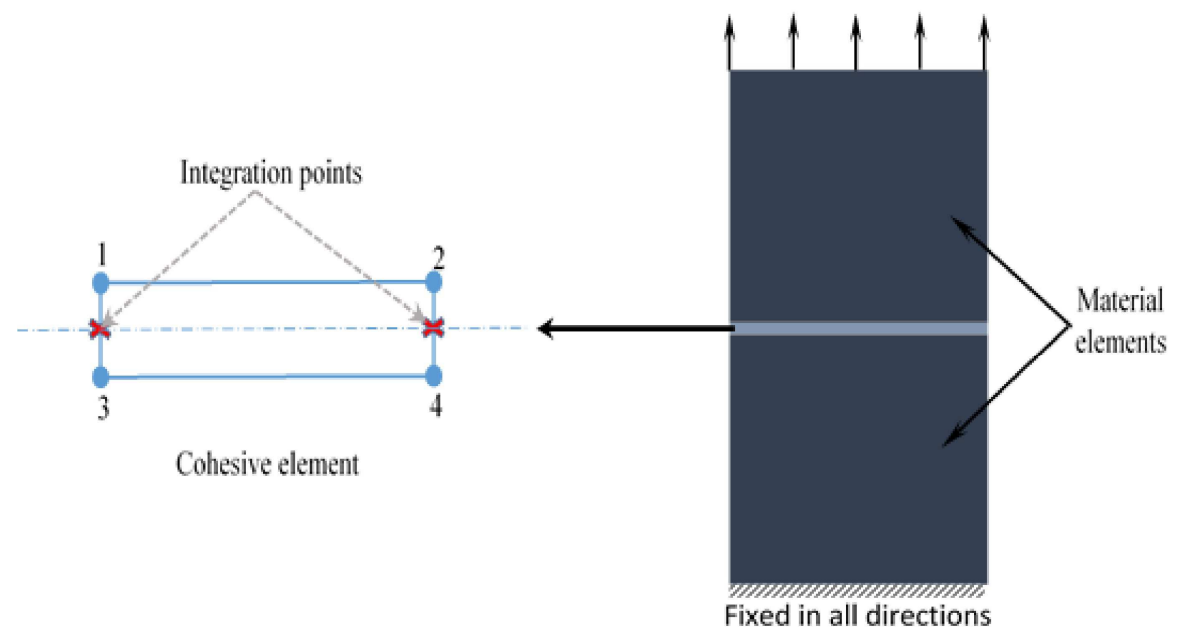

Figure 5. Implementation of the CE in the FE model.

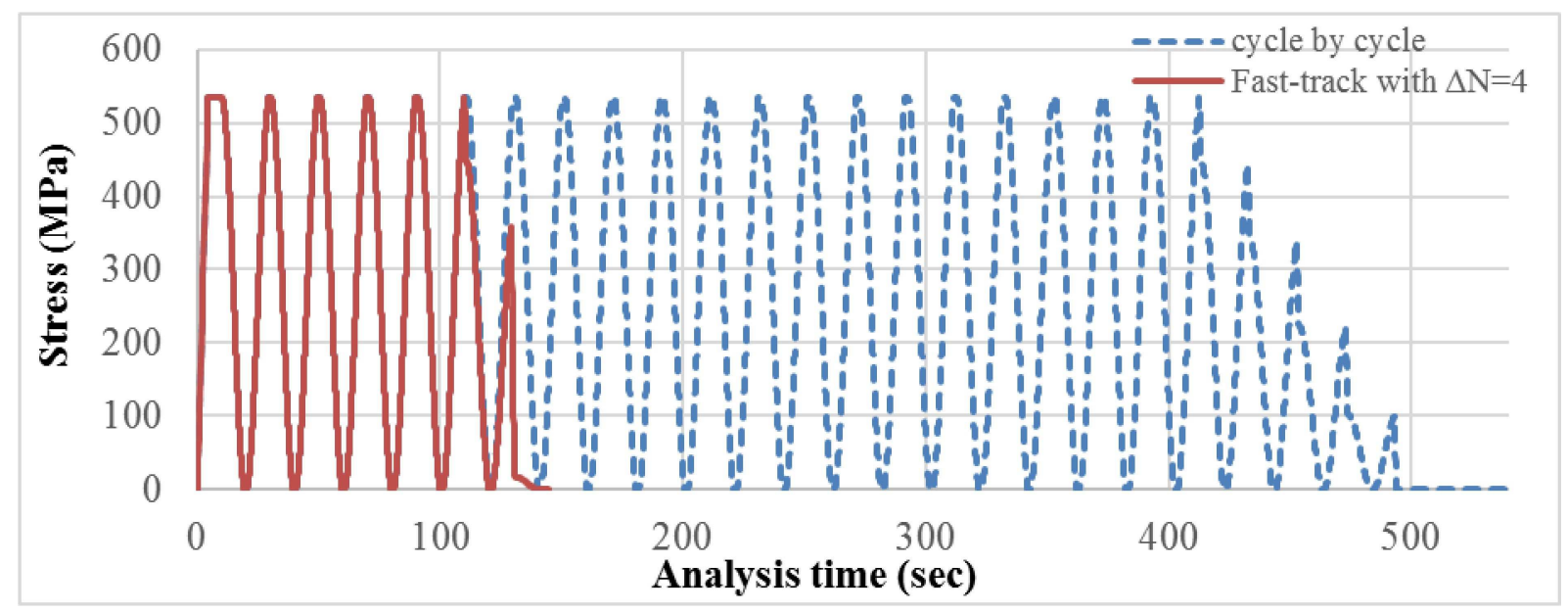

Figure 6. Cyclic stress as a function of time.
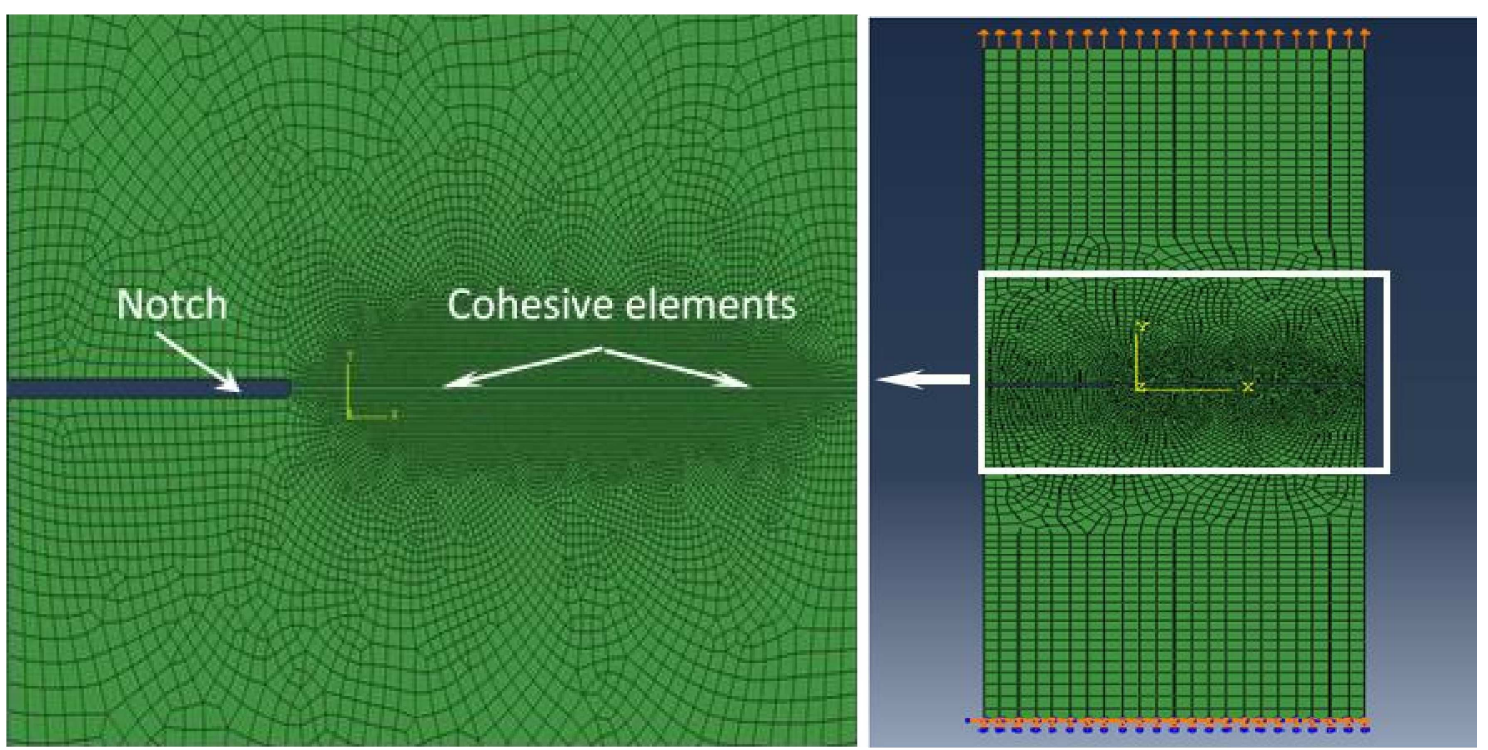

Figure 7. Boundary conditions and loading for FE model. 


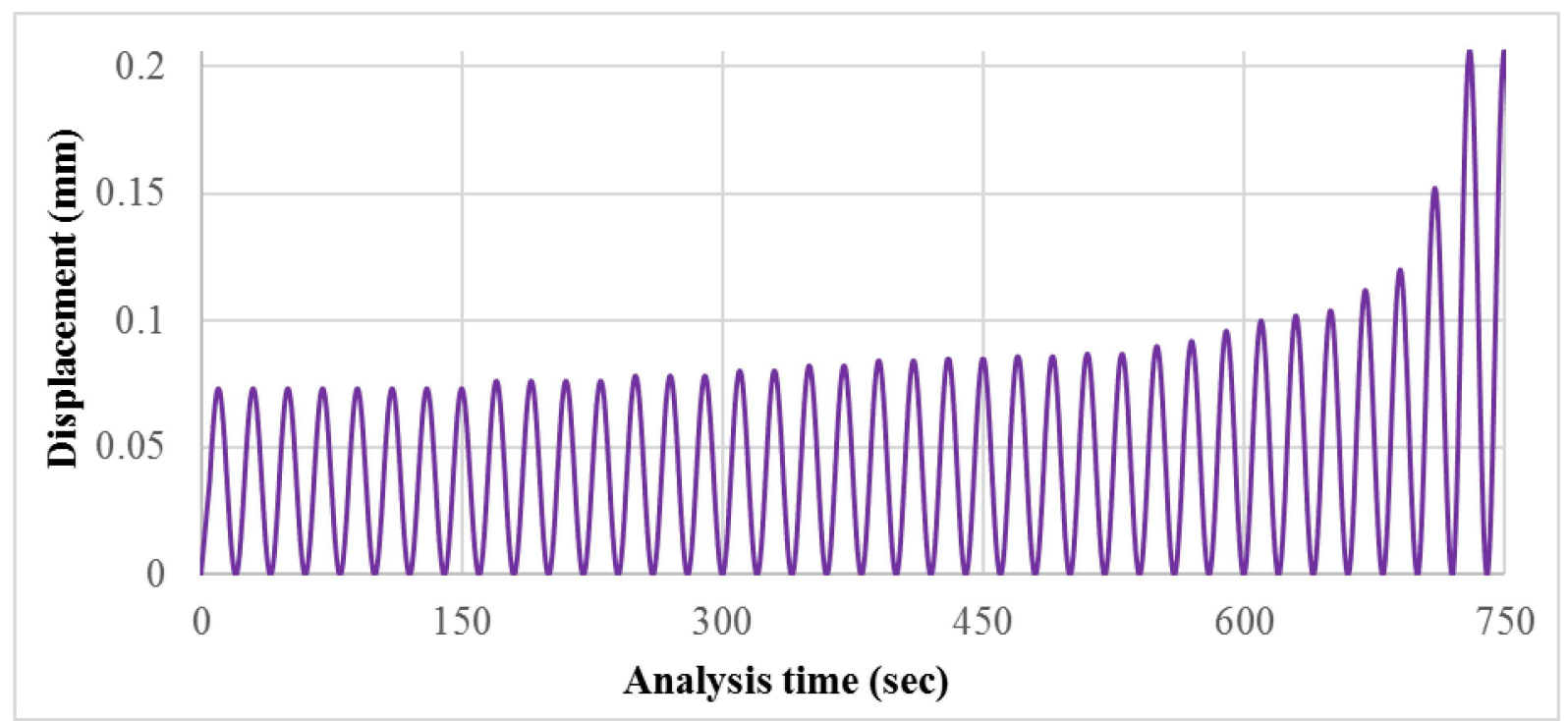

Figure 8. Load as a function of time.

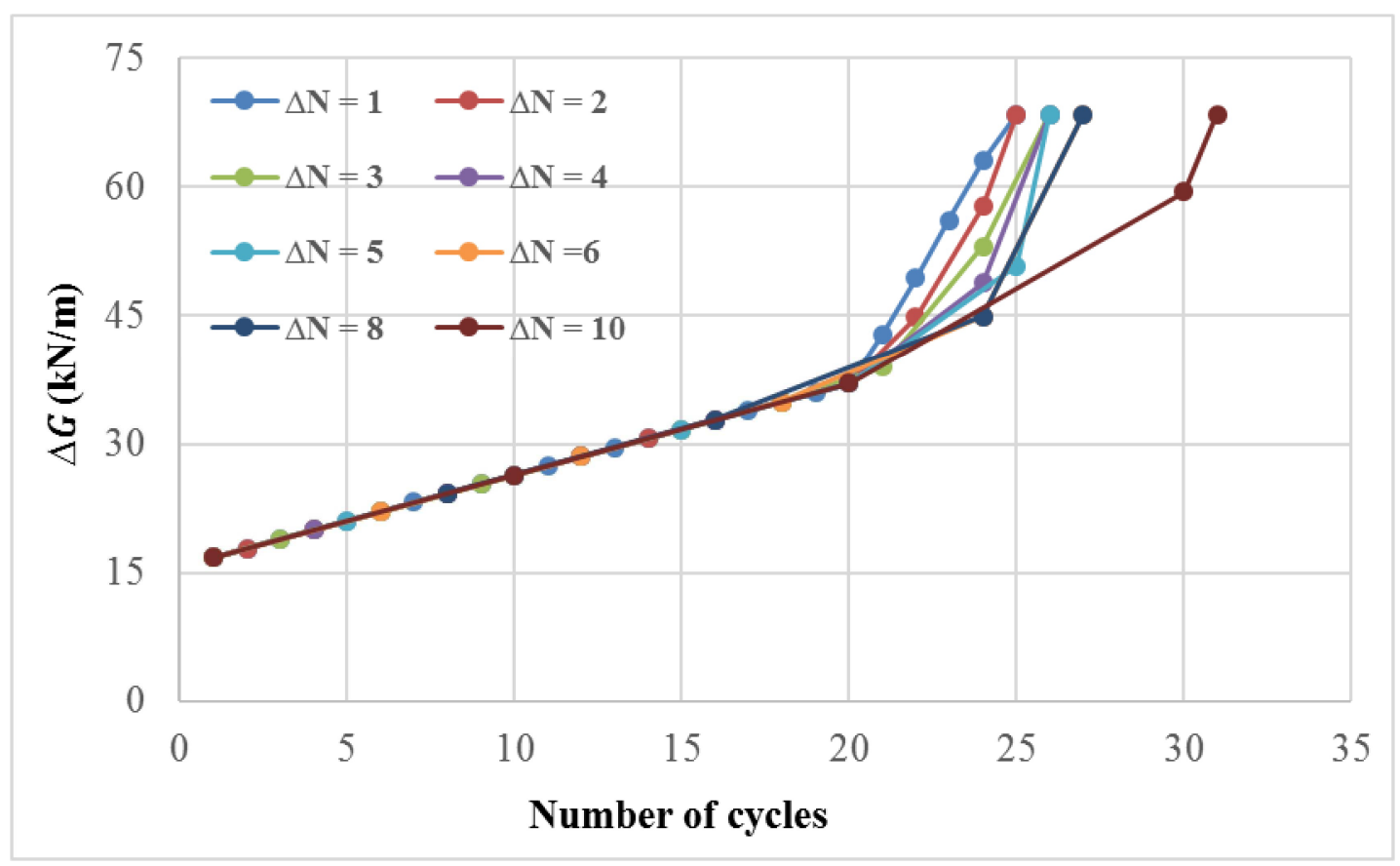

Figure 9. Dissipated energy with the number of cycles as a function of applied on the three-element model. 


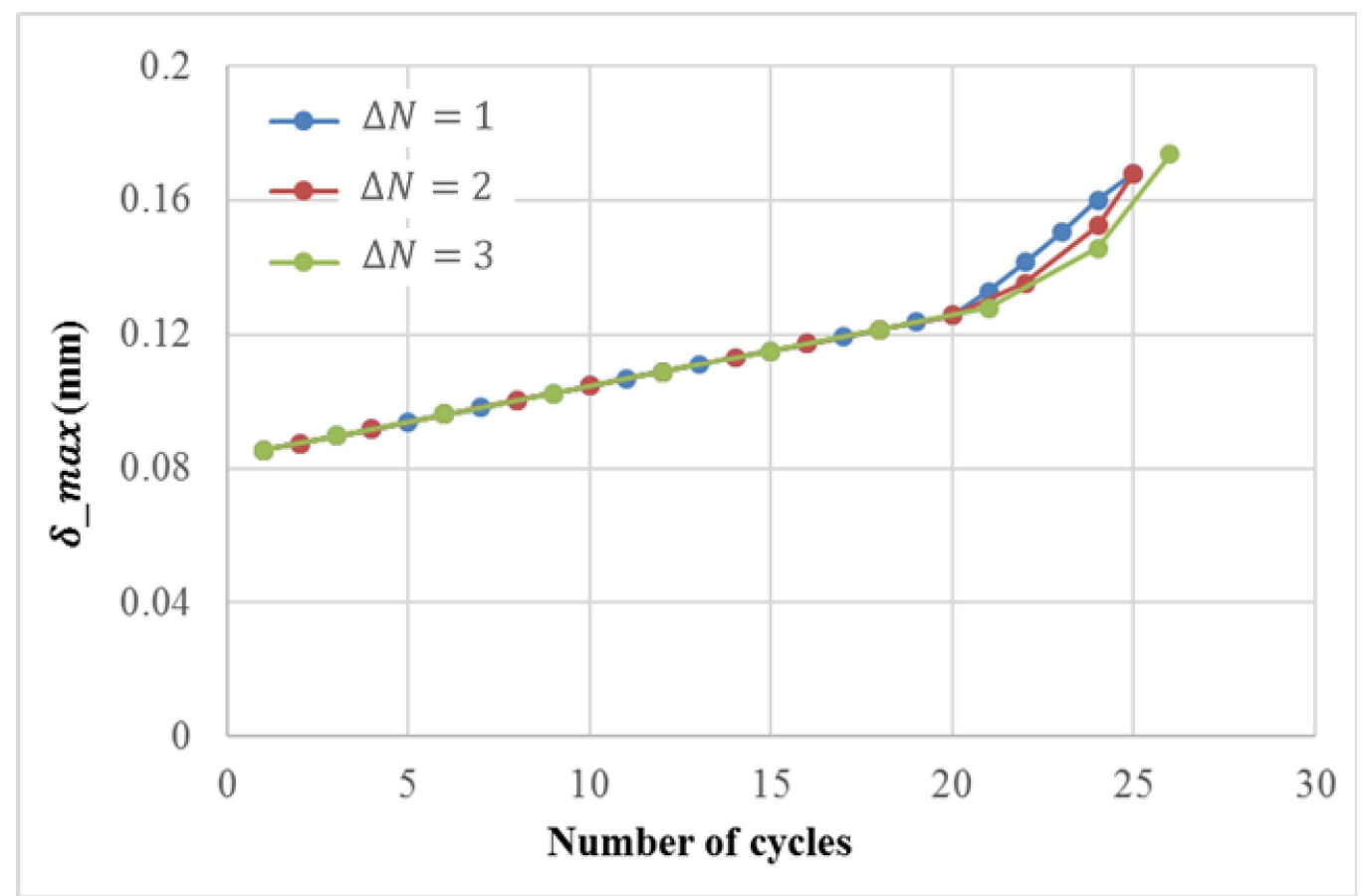

Figure 10. Change in $\eta_{\infty}$. with the number of cycles for three values of applied on the three-element model.

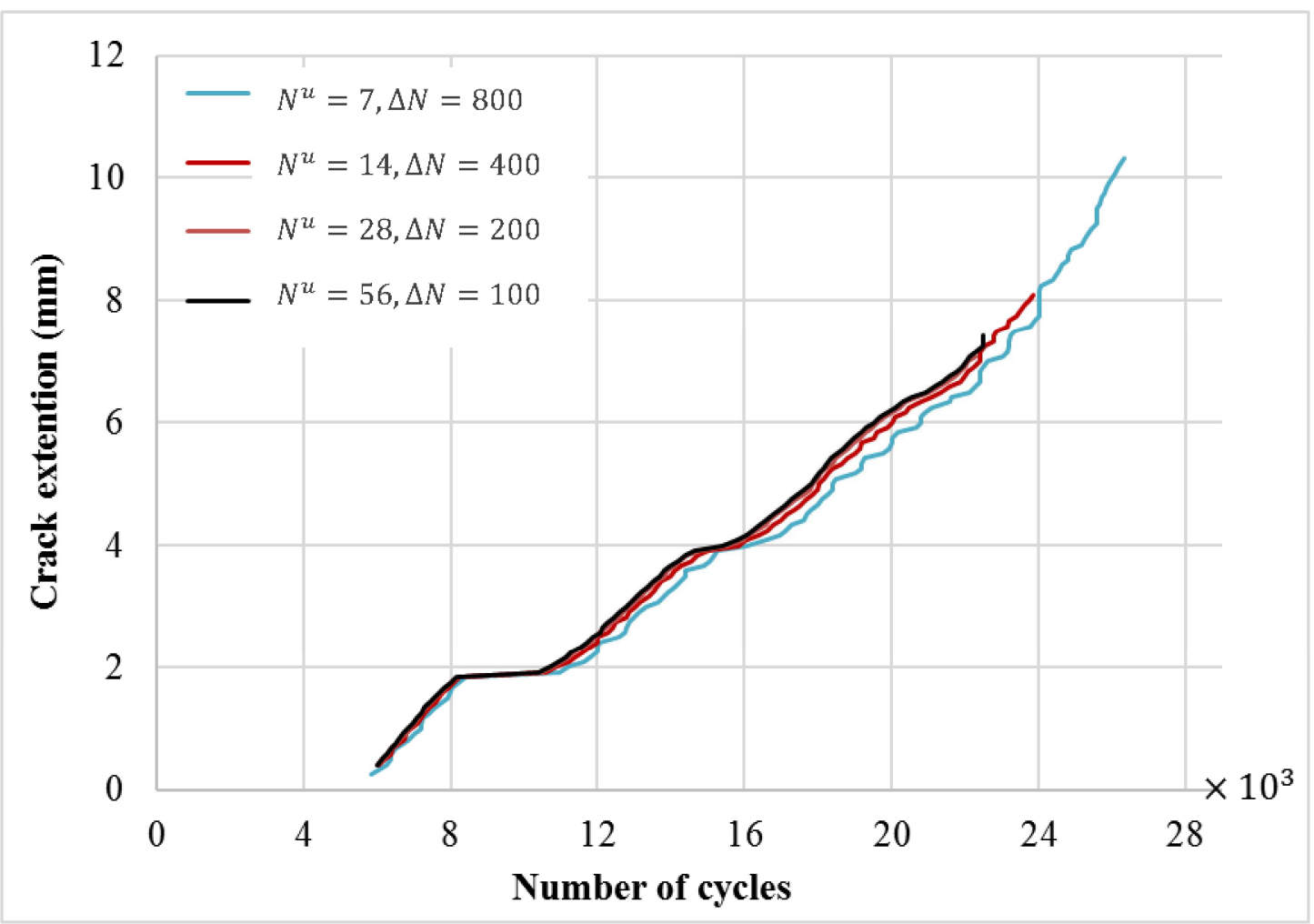

Figure 11. Crack length prediction for reasonable values of $\mathrm{o}^{\text {? }}$ at $\mathrm{R}=0$ and a frequency of $0.05 \mathrm{~Hz}$. 


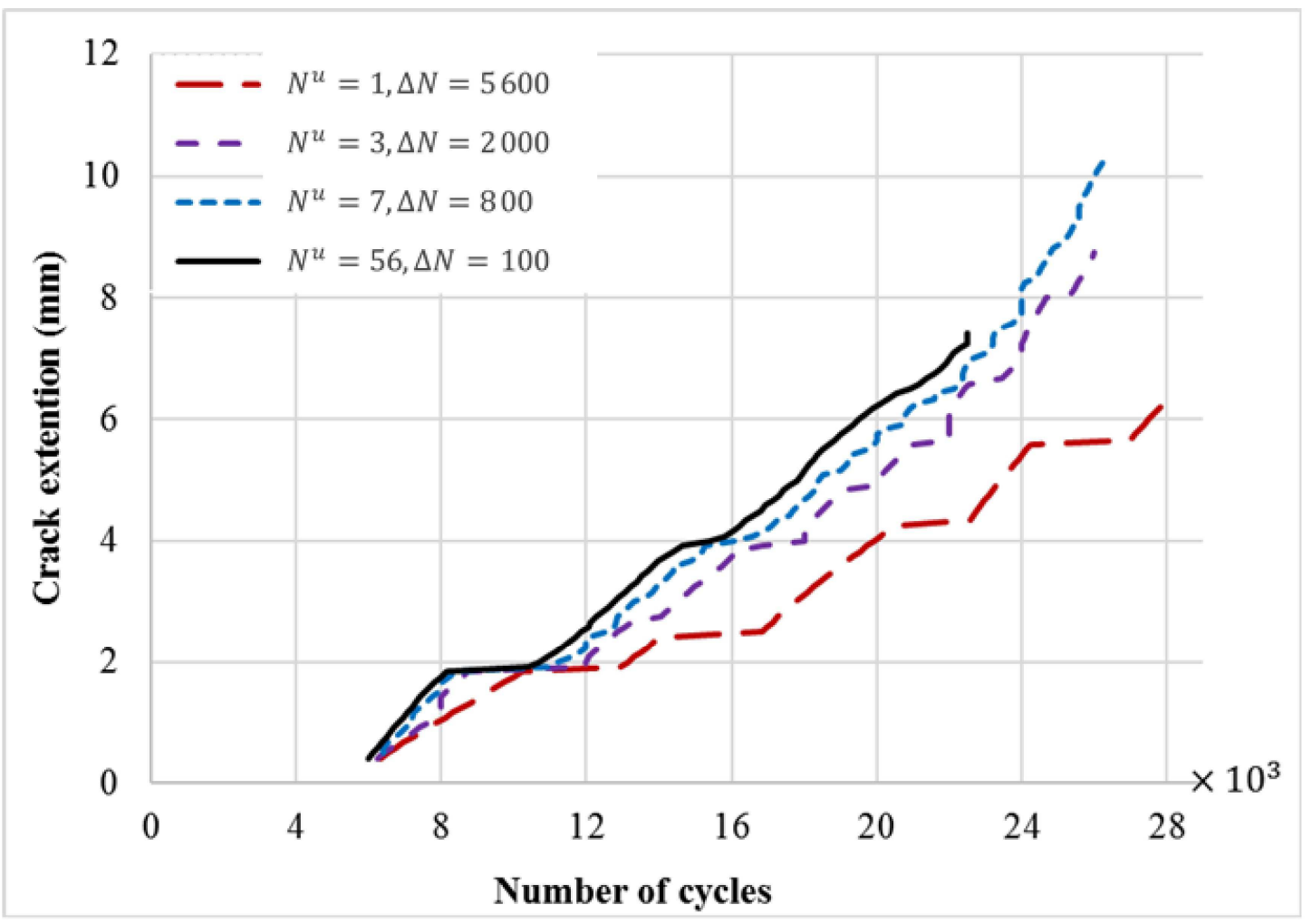

Figure 12. Crack length prediction for relatively small values of ${ }^{3}$ at $\mathrm{R}=0$ and a frequency of $0.05 \mathrm{~Hz}$.

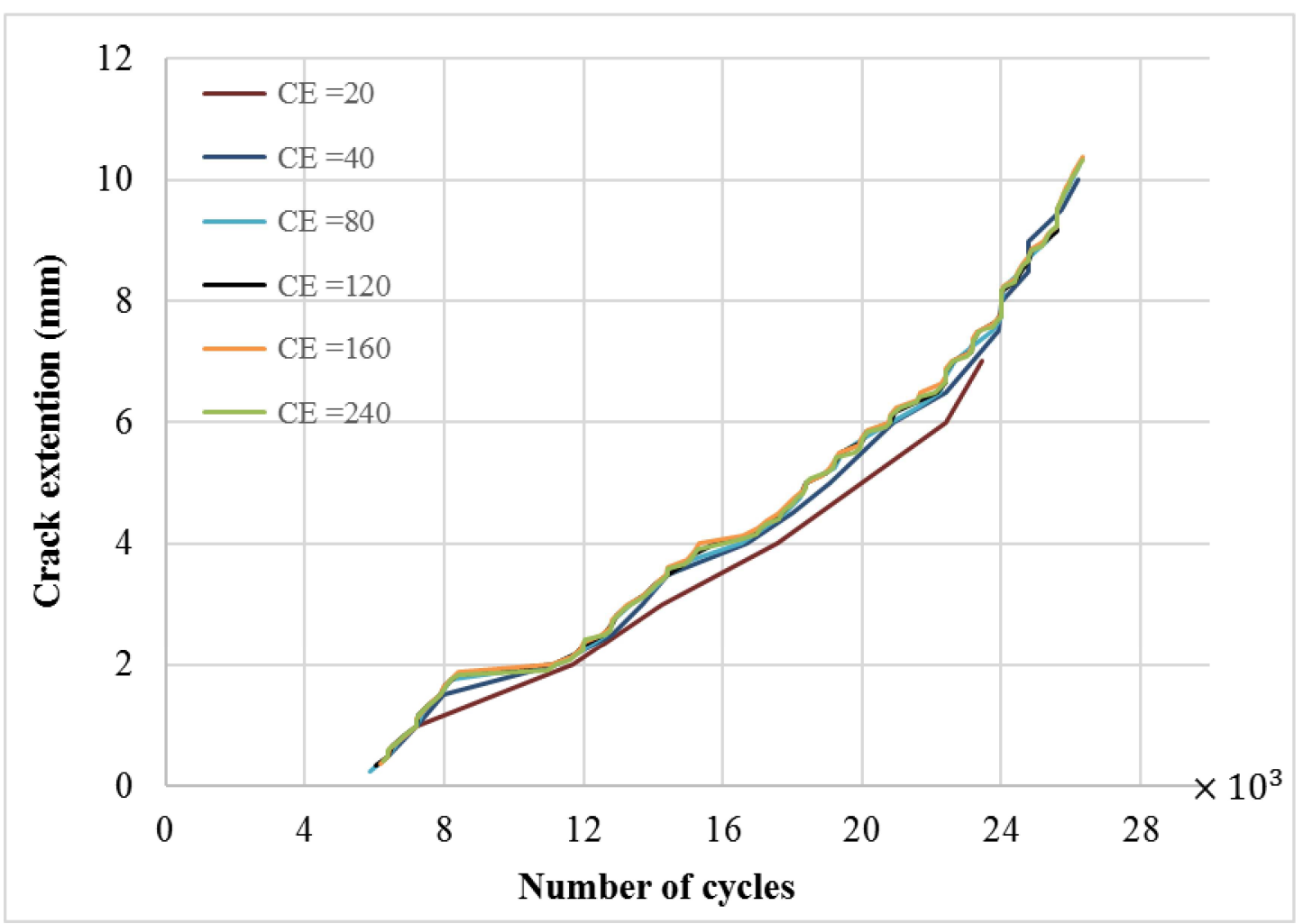

Figure 13. Importance of the number of cohesive elements in the cohesive zone. 


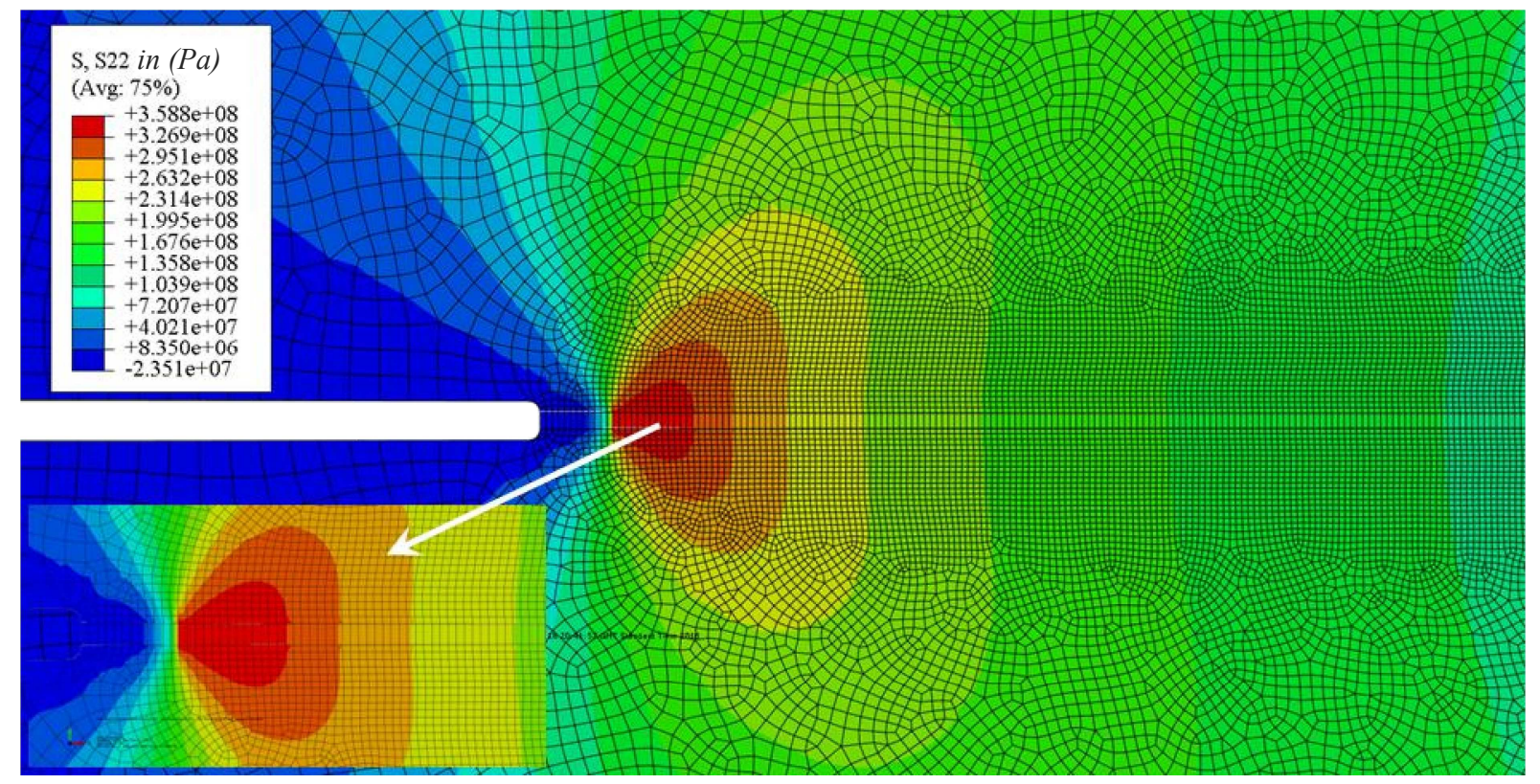

Figure 14. Stress field (measured in Pascal) with 140 cohesive elements used in

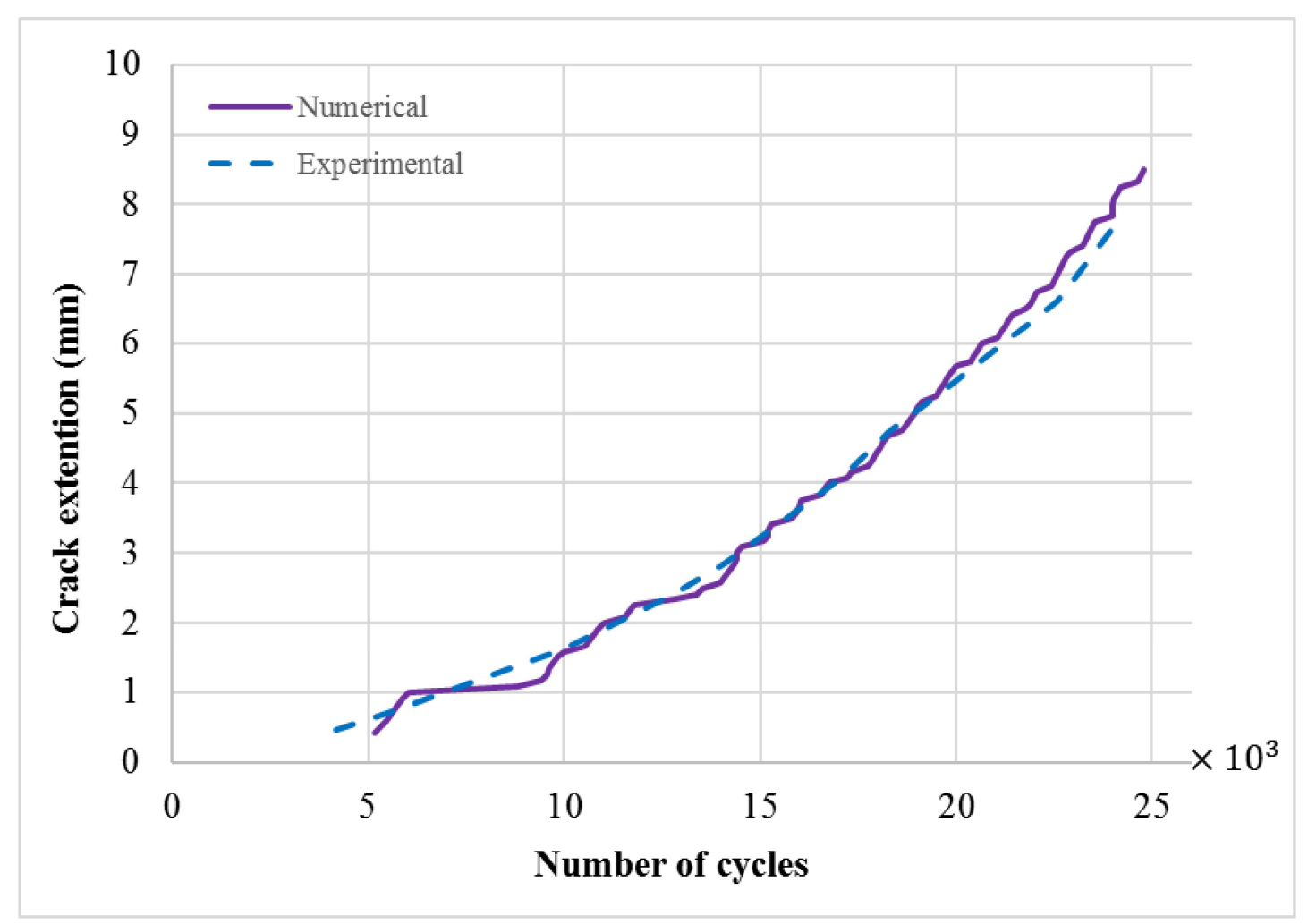

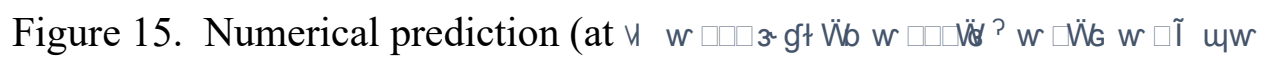

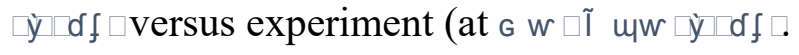

